\title{
CORRECTION
}

\section{Correction to: Linarin Protects against Cadmium-Induced Osteoporosis Via Reducing Oxidative Stress and Infammation and Altering RANK/ RANKL/OPG Pathway}

\author{
Yating Yang ${ }^{1,2} \cdot$ Ruining Cheng ${ }^{2} \cdot$ Jingyun $\mathrm{Liu}^{2} \cdot$ Jing Fang ${ }^{2} \cdot$ Xiaojing Wang $^{2} \cdot$ Yingxue Cui $^{2} \cdot$ Pan Zhang $^{2} \cdot$ Bin Du $^{1,3}$ (D)
}

Published online: 14 January 2022

○) Springer Science+Business Media, LLC, part of Springer Nature 2022

Correction to: Biological Trace Element Research https://doi.org/10.1007/s12011-021-02967-w

The original version of this article unfortunately a mistake.

The affiliation labels in the author group is now updated.

The original article has been corrected.

Publisher's Note Springer Nature remains neutral with regard to jurisdictional claims in published maps and institutional affiliations.

The original article can be found online at https://doi.org/10.1007/ s12011-021-02967-w.

Bin Du

yangdubinbin@sina.com

$1 \quad$ Xi'an Jiao Tong University, Xi' an 710049, Shaanxi, China

2 Department of Geriatrics, Xi' an Ninth Hospital, No.151, East Section of South Second Ring Road, Beilin District, Xi' an 710054, Shaanxi, China

3 Department of Orthopaedics, Xi' an Ninth Hospital, No.151, East Section of South Second Ring Road, Beilin District, Xi' an 710054, Shaanxi, China 